\title{
Effect of restricting the legal supply of prescription opioids on buying through online illicit marketplaces: interrupted time series analysis
}

\author{
James Martin, ${ }^{1}$ Jack Cunliffe, ${ }^{2}$ David Décary-Hétu, ${ }^{3}$ Judith Aldridge ${ }^{4}$
}

${ }^{1}$ Department of Social

Sciences, Swinburne University,

Melbourne, Australia

${ }^{2}$ School of Social Policy,

Sociology and Social Research,

University of Kent, Canterbury,

Kent CT2 7NF, UK

${ }^{3}$ École de criminologie,

Université de Montréal,

Montréal, Canada

${ }^{4}$ School of Law, University of

Manchester, Manchester, UK

Correspondence to: J Cunliffe

j.d.cunliffe@kent.ac.uk

Additional material is published

online only. To view please visit the journal online.

Cite this as: $B M J$ 2018;361:k2270 http://dx.doi.org/10.1136/bmj.k2270

Accepted: 22 April 2018

\author{
Abstract \\ Objective \\ To examine the effect on the trade in opioids through \\ online illicit markets ("cryptomarkets") of the US \\ Drug Enforcement Administration's ruling in 2014 to \\ reschedule hydrocodone combination products. \\ Design \\ Interrupted time series analysis. \\ Setting \\ 31 of the world's largest cryptomarkets operating from \\ October 2013 to July 2016.
}

Main outcome measures

The proportion of total transactions, advertised and active listings for prescription opioids, prescription sedatives, prescription steroids, prescription stimulants, and illicit opioids, and the composition of the prescription opioid market between the US and elsewhere.

Results

The sale of prescription opioids through US cryptomarkets increased after the schedule change, with no statistically significant changes in sales of prescription sedatives, prescription steroids, prescription stimulants, or illicit opioids. In July 2016 sales of opioids through US cryptomarkets represented $13.7 \%$ of all drug sales (95\% confidence interval $11.5 \%$ to $16.0 \%$ ) compared with a modelled estimate of $6.7 \%$ of all sales (3.7\% to $9.6 \%$ ) had the new schedule not been introduced. This corresponds to a 4 percentage point yearly increase in the amount of trade that prescription opioids represent in the US market, set against no corresponding changes for comparable products or for prescription opioids

\section{WHAT IS ALREADY KNOWN ON THIS TOPIC}

The over-supply of opioid analgesics has contributed to the quadrupling of deaths from overdose in the United states since 1999

Limiting the legal supply of these drugs through the US Drug Enforcement Administration's ruling in 2014 to reschedule hydrocodone combination products, narrowed the circumstances in which opioids could be prescribed and stopped automatic repeat prescriptions

There are concerns that opioid users will source their drugs from illicit markets (cryptomarkets) rather than from pharmacies

\section{WHAT THIS STUDY ADDS}

The proportion of US cryptomarket drug trade attributable to prescription opioids increased immediately after the schedule change, with no statistically significant changes in other drug categories

The composition of the prescription opioid supply on cryptomarkets also changed, with fentanyl being the least purchased drug in July to September 2014, then the second most frequently purchased drug by July 2016 sold outside the US. This change was first observed for sales, and later observed for product availability. There was also a change in the composition of the prescription opioid market: fentanyl was the least purchased product during July to September 2014, then the second most frequently purchased by July 2016.

Conclusions

The scheduling change in hydrocodone combination products coincided with a statistically significant, sustained increase in illicit trading of opioids through online US cryptomarkets. These changes were not observed for other drug groups or in other countries. A subsequent move was observed towards the purchase of more potent forms of prescription opioids, particularly oxycodone and fentanyl.

\section{Introduction}

Since 1999, deaths from overdose in the United States have quadrupled, ${ }^{1}$ in large part due to the over-supply of opioid analgesics. ${ }^{23}$ Recent evidence suggests that a "supply-side" approach-to limit the legal supply of these products-might have some utility, with research showing a reduction in the number of prescriptions issued for opioid analgesics in the United States between 2010 and $2015 .^{4}$ Although the legitimate supply of opioids might have decreased, overall consumption will remain unchanged if users decide to source their drugs from illicit markets rather than from pharmacies.

The general efficacy of supply side interventions in drug markets is, however, under-researched. ${ }^{5}$ Although understanding has been limited by a lack of detailed information connected to illicit drug supply, knowledge has improved in recent years with the emergence of online illicit marketplaces, or "cryptomarkets." These cryptomarkets share many characteristics with legal online marketplaces such as eBay, including the provision of a decentralised digital marketplace in which geographically disparate vendors create "seller pages" to advertise goods for sale, and the use of customer feedback scores to rank sellers in terms of perceived product quality and service. ${ }^{6-8}$ Cryptomarkets facilitate anonymous use through their "darknet" location and payment by cryptocurrencies such as Bitcoin..$^{7-9}$

The internet has facilitated the sale of licit and illicit drugs for more than 15 years, ${ }^{10-13}$ but when the first cryptomarket, Silk Road 1, came online in 2011, illicit drugs began to be traded in large quantities. The annual turnover of drug sales conducted through cryptomarkets is estimated to be in the hundreds of millions of dollars, ${ }^{14}$ with most transactions involving 
recreational drugs (eg, cannabis, “ecstasy”). Before 2014, prescription drugs represented slightly less than $10 \%$ of all cryptomarket sales. ${ }^{14}{ }^{15}$ People who buy through cryptomarkets are believed to be predominantly male, young ( $<25$ years), educated, employed, and white. ${ }^{16-21}$

Since 2011, cryptomarkets have been analysed through the digital traces they leave online, ${ }^{22}$ using automated software "crawlers" that collect publicly available data hosted on websites. The wealth of data available to researchers employing digital trace analysis includes the aliases and purported country level locations of drug vendors and the countries to which they are willing to make shipments. From each product listing posted by vendors on the marketplace, the drug type, price, and quantity can be determined, alongside customer feedback. Using these data, researchers have been able to track the growth of drug trading through the darknet, ${ }^{14} 15$ determining overall size, composition, and geographical distribution. ${ }^{20-25}$ Feedback posted by customers are used by researchers as a proxy for estimating numbers of transactions and revenues generated by drug vendors.

In this study we analysed cryptomarket data to determine the effect of a specific supply side intervention-the Drug Enforcement Administration's ruling in October 2014 to reschedule hydrocodone combination products, the most popularly prescribed opioid analgesics in the US at that time. ${ }^{26}$ The administration's decision to move hydrocodone combination products from schedule III to the more restrictive schedule II category ${ }^{1}$ substantially increased the difficulty with which patients could access these products by narrowing the circumstances in which they should be prescribed and removing the ability to obtain repeat prescriptions without a new script from a doctor.

Numerous studies conducted at regional and state levels indicate a substantial and sustained decrease in sales of hydrocodone combination products in the period immediately after the scheduling change. ${ }^{26-31}$ Nationally, prescriptions for hydrocodone combination products decreased by $26 \%$ between June 2013 and June 2015. ${ }^{32}$ Restrictions to the supply of hydrocodone combination products had the unintended consequences of a displacement towards use of less potent, over-the-counter opioid products (eg, Tylenol, with codeine (McNeil Consumer Healthcare, PA) $)^{26-33}$ and switching to illicit market substitutes, such as heroin and fentanyl. ${ }^{29-34}$ One study $^{34}$ suggested that the growing use of heroin and fentanyl in the US can be explained by the iron law of prohibition, whereby interventions to reduce supply, such as increased enforcement and changes to drug scheduling, lead to illicit markets dominated by higher potency products.

We investigated whether there is an association between the rescheduling of hydrocodone combination products and a subsequent sustained increase in trading of illicit prescription opioids on cryptomarkets, and whether, in line with the iron law of prohibition, any displaced illicit opioid market will enable access to more potent opioids in addition to hydrocodone equivalents.

\section{Methods}

To assess the impact of the US schedule change of hydrocodone combination products on the rates of listings (ie, products indicated as available for sale) and estimated sales for prescription opioids based on their location of origin, we used a unique longitudinal dataset from 31 different cryptomarkets that operated between September 2013 and July 2016. Setting these results against the cryptomarket sales for other prescription drugs and illicit opioids more generally, listed as originating from both within and outside the US, provided a comparator in relation to the schedule change in October 2014.

\section{Data}

We collected data using the web crawling software DATACRYPTO, ${ }^{35}$ which systematically looks for hyperlinks on cryptomarket web pages and downloads all the HTML pages it can find on the cryptomarkets. When the software has finished collecting data, it switches to its scraping mode and extracts the relevant information from web pages (eg, title of listings, name of vendors, type of drug). An independent panel responsible for overseeing a report on the online sales of illicit drugs for the Netherlands Ministry of Justice and Security ${ }^{14}$ found DATACRYPTO to be accurate and sufficiently reliable to inform on the current state of online illicit drug sales. The tool has also been found to have good validity by other researchers ${ }^{36}$ and has been used in many peer reviewed publications. ${ }^{14-40}$

Our analyses are based on data collected from 31 cryptomarkets in operation between 12 September 2013 and 18 July 2016, including all the largest English language sites (Alphabay, Nucleus, Dreammarket, Agora, Abraxas, Evolution, Silk Road 2 (Silk Road Reloaded), and SR1). Although some operational differences exist across cryptomarkets, their basic infrastructure and function is broadly similar. We used DATACRYPTO to collect data typically once every two weeks, with each episode generating a full crawl of the market. As no human participants were involved, the institutional review board at the Université de Montréal deemed it not necessary to obtain an ethics certificate from it for this research.

We extracted three pieces of information from each product listing placed by a vendor: the drug type on offer, the country from where products would be shipped, and the number of customer feedbacks the listing had received in the 30 days before DATACRYPTO's crawl. Owing to variability across markets, it was not possible to use information on price or product quantity. The number of customer feedbacks associated with a listing is an established proxy used by researchers to estimate the number of transactions generated by that listing. ${ }^{15374142}$ This proxy will undercount actual sales because not all customers leave feedback; in 2016, researchers estimated that $71 \%$ of cryptomarket transactions generated customer feedback. ${ }^{14}$ We also 
present our results using counts of total listings as well as only those listings that are "active" in having at least one customer feedback within the past 30 days, a strategy used by researchers to account for dormant or historical listings, as well as listings only recently placed on the marketplace. ${ }^{1424}$

In total, 10930608 separate transactions were recorded in the dataset, of which we consider only those 2968217 (27.2\%) that occurred in the 30 days before the date of each crawl by DATACRYPTO. These transactions are related to 2686396 product listings, of which 1613776 (60.1\%) were classified as drug related. More than a quarter (445080 or $27.6 \%$ ) of these drug listings were active.

\section{Analysis}

We focused on six product types: prescription opioids, prescription sedatives, prescription steroids, prescription stimulants, other prescription drugs, and illicit opioids (eg, heroin). Supplementary appendix 1 lists the individual drugs within each of these product types. We defined products as originating from within the US or elsewhere. Previous work ${ }^{24-43}$ has found that the main countries of origin for drugs traded through cryptomarkets were, in descending order: Europe (predominantly the United Kingdom, Germany, and the Netherlands), the US, Australia, and Canada. One study found that most listings originating in the US were available only domestically, whereas those from Europe were more likely to be available to international buyers. ${ }^{43}$

It is also not possible to report the absolute numbers of products or sales generated by cryptomarkets using the dataset we collected. Data collection crawls will always capture marketplace activity only imperfectly, and to an extent partially, and to reduce the uncertainty in our data, our results point to approximated estimates. ${ }^{15-40}$ Therefore, under the assumption that the data collected are a representative subsample of the total number of drug types available on cryptomarkets, our analysis focuses on the percentage that each of our six product types (see supplementary appendix 1) represents of total drug listings. Descriptive statistics for each drug group and area of origin are presented in supplementary appendix 2 and show that there was a large amount of variation in the percentage of sales for each grouping, and this can be directly attributable to difficulties in collecting or processing such data and the short term volatility of the marketplaces.

In addition to descriptive statistics, we present an interrupted time series analysis ${ }^{44} 45$ of the percentage of drug sales on each day of the data collection period, with a slope change at the day of the schedule change on 6 October 2014, using the equation:

$$
P_{\text {tda }}=\beta_{\text {otda }}+\left(\beta_{1 \mathrm{tda}}+\beta_{2 \mathrm{tda}} X_{\mathrm{t}}\right) T+\varepsilon_{\text {tda }}
$$

where $P_{t d a}$ represents the percentage of total transactions at time $t$ attributable to each of six drug groupings, $d$, where $a$ represents originating from the US or not, $T$ represents the date of data collection in days from the beginning of the study (12 September 2013), and $X_{t}$ represents a dummy variable defined as zero before and 1 after the schedule change.
No other covariates were added to the model (eg, prices or package sizes) owing to constraints on data availability. To aid interpretation we scale and present parameters from the model on a yearly basis. The rationale for this is that if the rescheduling of prescription opioids caused an increase in the proportion of transactions for prescription opioids only within the US, this would be apparent by an increased rate of change of the percentage of that drug group with no other comparable change in other products or locations unaffected by the scheduling change.

Data manipulation was undertaken using the database management system software MySQL (Oracle, $\mathrm{CA})$, with the linear regression analysis conducted in Stata13 using Huber-White sandwich robust standard errors to account for a lack of normality in the dependents, heteroscedasticity, and data points with high leverage owing to the nature of the data collection process.

To identify which products were purchased we focused on the specific subtypes of opioid prescription drugs (hydrocodone, oxycodone, fentanyl, and tramadol, with their various brand names listed in supplementary appendix 1). We plotted the proportion of total online sales of prescription opioids attributable to each specific product over time.

\section{Patient and public involvement}

No patients or the public were involved in this research. As a result, no patient or the public informed the research questions and no patient was recruited. The public and select news organisations might be contacted to help disseminate the research findings.

\section{Results}

For each of the drug categories, figure 1 presents, on a quarterly basis, the percentage of transactions, active listings, and listings for products originating from within the US or from other countries. The only clear increase relating to transactions for prescription opioids was within the US. This increase first occurred within the transaction measure, before a comparable effect on the number of active listings and finally translating through to the total number of listings (fig 1).

Sales of prescription sedatives increased, although this appears only for active listings and it is unclear whether the increase occurred within transactions (the most relevant measure of usage), which varies between $7.5 \%$ and $11 \%$ of all drug transactions seemingly without pattern (fig 1). Results of the interrupted time series regressions, however, show that the rate of transactions involving prescription sedatives does not appear to have changed after the introduction of the new schedule (table 1).

Coefficients were estimated on a daily percentage rate basis and converted to a rate over a full year (multiplying by 365) to aid interpretation.

The regression coefficients $(\beta)$ and the standard error display the estimated change in the percentage of total transactions represented by each of the drug classifications and region of origin over a full year 

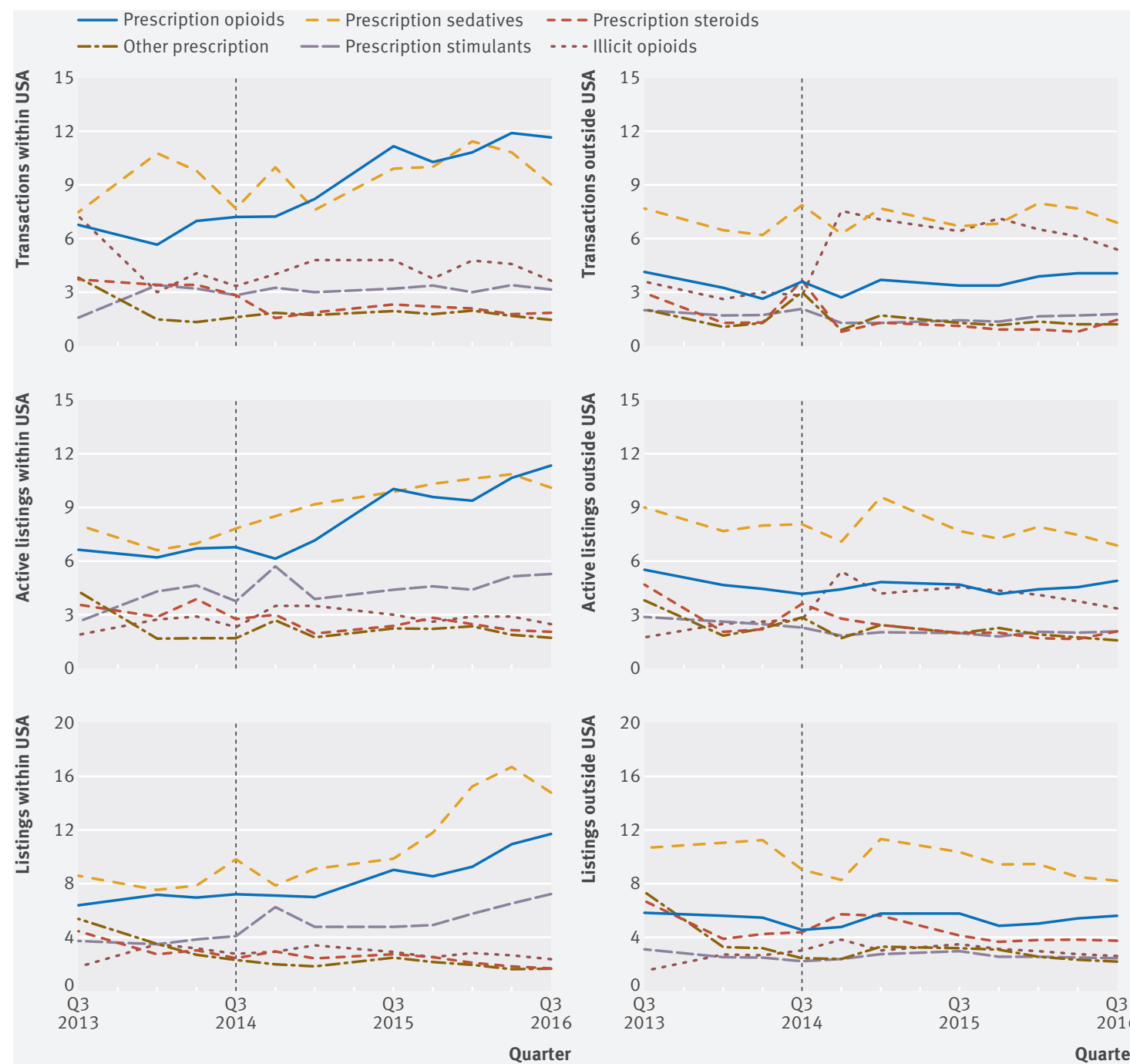

0

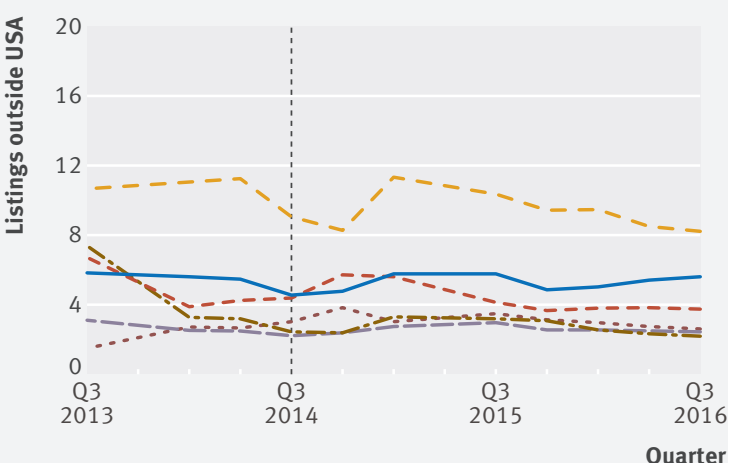

Fig 1 | Percentage of online drug transactions, active listings, and listings by drug category for products sold within the US compared with elsewhere, quarter 32013 to quarter 32016

(table 1). The point estimate for prescription sedatives from within the US of 4.468 before the schedule change therefore means that between 12 September 2013 and 6 October 2014 the percentage of sales within the US represented by prescription sedatives increased by just less than 4.5 percentage points per year. The variation in the recorded percentage in each web crawl, however, leads to a standard error of just less than 3 percentage points and a $P$ value of 0.13 (under the null hypothesis of zero) for prescription sedatives originating from the US. After the schedule change, there was no evidence of a change in transactions for prescription sedatives within the US. The same is true for almost all drug classifications, from all places of origin both before and after the schedule change, with the exception of illicit opioids, which showed a statistically significant increase before the schedule change followed by a decrease after change, although $P$ values associated with the standard errors border on the 5\% significance level within the US; and of prescription opioids within the US after the schedule change, with a statistically significant 4 percentage points increase in transactions.

These regression results can be used to estimate by how much the percentage of all drugs sales attributable to prescription opioids increased between the schedule change to the end of the study period. The marginal percentages suggest that without the schedule change the percentage of sales represented by prescription opioids on the 18 July 2016 would be $6.7 \%$ of all drug sales (95\% confidence interval $3.7 \%$ to $9.6 \%$ ). When the effect of the schedule date slope change is included, however, the proportion increases to $13.7 \%$ of all drugs sales (11.5\% to $16.0 \%)$. This represents an approximate doubling of the percentage of the total drug sales through cryptomarkets within the US compared with no statistically significant change for the proportion of the same products outside the US, nor are there any meaningful changes to the proportion of sales for any other relevant drug category.

Figure 2 shows the proportion of transactions of prescription opioids that are attributable to the four 


\begin{tabular}{|c|c|c|c|c|c|c|}
\hline \multirow[b]{2}{*}{ Variables } & \multicolumn{5}{|c|}{ Prescription drugs } & \multirow[b]{2}{*}{ Illicit opioids } \\
\hline & Sedatives & Opioids & Steroids & Stimulants & Other & \\
\hline \multicolumn{7}{|l|}{ Within US } \\
\hline \multicolumn{7}{|l|}{ Before change: } \\
\hline$\beta$ coefficient & 4.468 & 2.383 & -0.789 & 1.914 & -5.904 & 10.027 \\
\hline SE & 2.955 & 4.002 & 1.080 & 2.106 & 5.585 & 4.899 \\
\hline$P$ value & 0.13 & 0.55 & 0.47 & 0.36 & 0.29 & $<0.05$ \\
\hline \multicolumn{7}{|l|}{ After change: } \\
\hline$\beta$ coefficient & 0.797 & 3.946 & -0.166 & -0.197 & 0.948 & -4.185 \\
\hline SE & 0.937 & 1.269 & 0.343 & 0.668 & 0.618 & 2.042 \\
\hline$P$ value & 0.40 & $<0.01$ & 0.63 & 0.77 & 0.13 & $<0.05$ \\
\hline \multicolumn{7}{|l|}{ Outside US } \\
\hline \multicolumn{7}{|l|}{ Before change } \\
\hline$\beta$ coefficient & 1.725 & 1.598 & 0.300 & -0.460 & 0.456 & 5.242 \\
\hline SE & 3.419 & 1.323 & 0.871 & 1.015 & 0.515 & 1.789 \\
\hline$P$ value & 0.61 & 0.23 & 0.73 & 0.65 & 0.38 & $<0.001$ \\
\hline \multicolumn{7}{|l|}{ After change: } \\
\hline$\beta$ coefficient & -1.496 & -0.162 & -0.235 & 0.218 & -0.166 & -0.679 \\
\hline SE & 0.898 & 0.348 & 0.229 & 0.267 & 0.204 & 0.470 \\
\hline Pvalue & 0.10 & 0.64 & 0.31 & 0.42 & 0.42 & 0.15 \\
\hline
\end{tabular}

by 365 ) to aid interpretation.

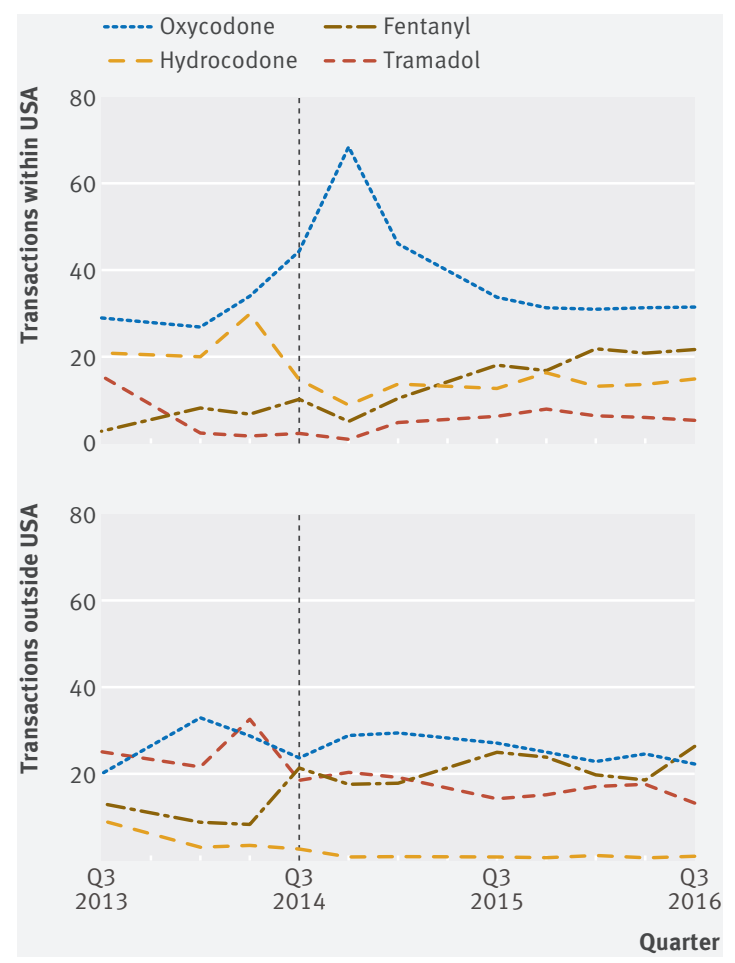

Fig 2 | Percentage of online transactions for prescription opioids sold within the US compared with elsewhere, quarter 32013 to quarter 32016

Europe was purchased by a US customer. Nevertheless, cryptomarket users often prefer buying and selling from vendors in the same country; international shipments carry risks of loss, interception by officials, and increased delivery times. A study of cryptomarkets in Australia found that local vendors were often preferred over international counterparts, despite substantially higher prices. ${ }^{24}$ Another study ${ }^{36}$ also noted the downward trends of international sales and therefore an increase in domestic sales, and yet another study ${ }^{47}$ found that drug trading through cryptomarket is heavily constrained by offline geography. This preference for domestic trading, combined with the relatively large numbers of US drug vendors trading in cryptomarkets, leads us to presume that most sales of prescription drugs by US vendors will be sold to customers based in the US. Conversely, most transactions generated by non-US vendors will not be sold to US customers.

The results of our interrupted time series suggest the possibility of a causal relation between the schedule change and the percentage of sales represented by prescription opioids on cryptomarkets. Our analysis cannot rule out other possible causal explanatory factors, but our results are consistent with the possibility that the schedule change might have directly contributed to the changes we observed in the supply of illicit opioids. This possibility is reinforced by the fact that the increased availability and sales of prescription opioids on cryptomarkets in the US after the schedule change was not replicated for cryptomarkets elsewhere. in the US doubled from $6.7 \%$ to $13.7 \%$, which corresponds to a yearly increase of 4 percentage points in market share. It is not possible to determine the location of buyers from cryptomarket data. We cannot know, for example, if a drug shipped from a vendor in 
Our results are consistent with the possibility of demand led increases. The first increase observed for prescription opioids was for actual sales (fig 1); with increases for active listings, and then all listings, following. One explanation is that cryptomarket vendors perceived an increase in demand and responded by placing more listings for prescription opioids and thereby increasing supply. Our results are also consistent with the iron law of prohibition ${ }^{34}$ insofar as we identified the largest sales increases for more potent prescription opioids-specifically, oxycodone and fentanyl. Cryptomarkets may function as a supply gateway ${ }^{48}$ : customers who initially sought out illicit hydrocodone on cryptomarkets after the schedule change might then have favoured more potent opioids available on the marketplace.

The shift towards users accessing drugs through cryptomarkets might make it more difficult to reduce the harms associated with prescription opioids; it was possible to control the quality and quantity of legal prescription drugs used. With the move to an illicit market it becomes more difficult to track individual use of prescription opioids, and to offer treatment and help to users. The iron law of prohibition also suggests that the move to an illicit market is associated with use of increasingly potent drugs. We found that users were first buying oxycodone followed by fentanyl. Drug users adapt to their changing environment and are able to source drugs from new distribution channels if needed, even if that means by illegal means. In a context of high demand, supply side interventions are therefore likely to push opioid users towards illicit supplies, which may increase the harms associated with their drug use and make monitoring more difficult. These problems may be minimised, however, through the implementation of additional, demand oriented policy responses. One researcher ${ }^{4950}$ provides multiple alternative and complementary strategies to supply side interventions that focus on the demand for illicit drugs: providing reliable treatment options, dealing with over-prescribing, and making more information available about the nature and dangers of prescription opioid use to reduce the associated stigmas. These alternatives are known to have an impact on drug use and could be employed before and after schedule changes to alleviate their negative impacts.

\section{Limitations of this study}

The main limitation of our study concerns causal mechanisms. Although our results show an increase in sales of prescription opioids on cryptomarkets after the schedule change, contemporaneous factors might also have played a causal role. These could include the effect of other public policies enacted over the same period; however, we do not know of any other policies that were implemented as widely as the Drug Enforcement Administration's schedule change. ${ }^{31} 32$ Other potential causal factors include a more general increase in demand unrelated to the schedule change in the US, or a more general awareness among this group of drug users that they can source prescription drugs illicitly through cryptomarkets. While these potential changes cannot be ruled out, it is unlikely that they occurred at the same time as the schedule change. Furthermore, the flat trend we identified in illicit sales across all other drug categories, even for those drugs that would be likely to appeal to a similar type of user, suggests that a general awareness of cryptomarkets was not increased at the same time within the US population of drug users.

A second limitation concerns the validity of the data collected using DATACRYPTO software. Researchers can never be certain that a web crawler has obtained all of the content on a cryptomarket during a data sweep. Regardless, no concerns have arisen through multiple evaluations of the DATACRYPTO dataset. Moreover, repeated evaluations of data collected using DATACRYPTO are consistent with each other, thereby reducing the likelihood that the software was interrupted while web crawling.

A third limitation is that our assessment of the geographical source and destination of drugs based on public information cannot be independently confirmed. A vendor could advertise shipping from the US but be located in Mexico, Canada, or elsewhere. The customer feedback system limits this possibility as buyers would quickly feedback about increased delivery times of drugs received from another country. Cryptomarkets are competitive settings ${ }^{8-37}$ and vendors who cheat and act opportunistically are not likely to remain active for extended periods and are therefore unlikely to make up a sizeable proportion of our vendor population. Similarly, it is possible that some US based vendors shipped their drugs to customers in other countries. Recent trends analysis by researchers ${ }^{36-47}$ as well as qualitative analysis of forums show that customers are reticent to order from foreign vendors. We do not therefore expect our estimates to be impacted substantially by these limitations.

We thank Alex Stevens and Letizia Paoli for their constructive feedback. Contributors: JM conceived the study and is the guarantor. DD-H and JA collected the data. JC ran the analyses. All authors were involved in the design and writing of the paper. The corresponding author attests that all listed authors meet authorship criteria and that no others meeting the criteria have been omitted.

Funding: The data collection was funded in parts by the Social Sciences and Humanities Research Council of Canada (\#4302015-01089), Macquarie University internal grants, and the Wetenschappelijk Onderzoek-en Documentatiecentrum (WODC) from the Ministry of Justice and Security of the Netherlands. The researchers remained independent from the funders at all time. The funders were not consulted before or during the work.

Competing interests: All authors have completed the ICMJE uniform disclosure form at www.icmje.org/coi_disclosure.pdf and declare: this research was funded by a Macquarie University research development grant; no financial relationships with any organisations that might have an interest in the submitted work in the previous three years, no other relationships or activities that could appear to have influenced the submitted work.

Ethical approval: Not required.

Data sharing: No additional data available.

Transparency: The lead author (JM) affirms that the manuscript is an honest, accurate, and transparent account of the study being reported; that no important aspects of the study have been omitted; and that any discrepancies from the study as planned have been explained.

This is an Open Access article distributed in accordance with the Creative Commons Attribution Non Commercial (CC BY-NC 4.0) license, 
which permits others to distribute, remix, adapt, build upon this work non-commercially, and license their derivative works on different terms, provided the original work is properly cited and the use is noncommercial. See: http://creativecommons.org/licenses/by-nc/4.0/.

1 Rudd RA, Seth P, David F, Scholl L. Increases in drug and opioidinvolved overdose deaths-United States, 2010-2015. MMWR Morb Mortal Wkly Rep 2016;65:1445-52. doi:15585/mmwr. mm655051e1

2 Volkow ND. America's addiction to opioids: heroin and prescription drug abuse. Senate Caucus on International Narcotics Control, 2014: 14.

3 Makary MA, Overton HN, Wang P. Overprescribing is major contributor to opioid crisis. BMJ 2017;359:j4792. doi:1136/bmj.j4792

4 Guy GPIr, Zhang K, Bohm MK, et al. Vital Signs: Changes in Opioid Prescribing in the United States, 2006-2015. MMWR Morb Mortal Wkly Rep 2017;66:697-704. doi:15585/mmwr.mm6626a4

5 Greenfield VA, Paoli L. Research as due diligence: What can supply-side interventions accomplish and at what cost? Int I Drug Policy 2017;41:162-3. doi:1016/j.drugpo.2017.01.010

6 Barratt MJ. Silk Road: eBay for drugs. Addiction 2012;107:683. doi:1111/j.1360-0443.2011.03709.x

7 Martin J. Lost on the Silk Road: Online drug distribution and the “cryptomarket”. Criminol Crim Justice 2014a;14:351-67. doi:1177/1748895813505234

8 Martin J. Drugs on the Dark Net: How Cryptomarkets are Transforming the Global Trade in Illicit Drugs. Palgrave Macmillan, 2014b. doi:1057/9781137399052

9 Barratt MJ, Aldridge J. Everything you always wanted to know about drug cryptomarkets* (*but were afraid to ask). Int J Drug Policy 2016;35:1-6. doi:1016/j.drugpo.2016.07.005

10 Bloom BS, Iannacone RC. Internet availability of prescription pharmaceuticals to the public. Ann Intern Med 1999;131:830-3. doi:7326/0003-4819-131-11-199912070-00005

11 Littlejohn C, Baldacchino A, Schifano F, Deluca P. Internet pharmacies and online prescription drug sales: a cross sectional study. Drugs Educ Prev Policy 2005;12:75-80. doi:1080/0968763042000275326

12 Easton G. Clicking for pills. BMJ 2007;334:14-5. doi:1136/ bmj.39063.418391.68

13 Orizio G, Merla A, Schulz PJ, Gelatti U. Quality of online pharmacies and websites selling prescription drugs: a systematic review. J Med Internet Res 2011;13:e74. doi:2196/jmir.1795

14 Kruithof K, Aldridge J, Décary-Hétu D, Sim M, Dujso E, Hoorens S. Internet-facilitated drugs trade. RAND Corporation, 2016: 21-32.

15 Soska K, Christin N. Measuring the Longitudinal Evolution of the Online Anonymous Marketplace Ecosystem; Proceedings of the 23rd USENIX Security Symposium (USENIX Security'14); 2015; 33-48.

16 Van Hout MC, Bingham T. 'Silk Road', the virtual drug marketplace: a single case study of user experiences. Int I Drug Policy 2013a;24:385-91. doi:1016/j.drugpo.2013.01.005

17 Van Hout MC, Bingham T. 'Surfing the Silk Road': a study of users' experiences. Int J Drug Policy 2013b;24:524-9. doi:1016/i. drugpo.2013.08.011

18 Barratt MJ, Ferris JA, Winstock AR. Use of Silk Road, the online drug marketplace, in the United Kingdom, Australia and the United States. Addiction 2014;109:774-83. doi:1111/add.12470

19 Barratt MJ, Ferris JA, Winstock AR. Safer scoring? Cryptomarkets, social supply and drug market violence. Int J Drug Policy 2016;35:24-31. doi:1016/j.drugpo.2016.04.019

20 Van Buskirk J, Roxburgh A, Bruno R, et al. Characterising dark net marketplace purchasers in a sample of regular psychostimulant users. Int J Drug Policy 2016;35:32-7. doi:1016/j. drugpo.2016.01.010

21 Bancroft A, Scott Reid P. Concepts of illicit drug quality among darknet market users: Purity, embodied experience, craft and chemical knowledge. Int J Drug Policy 2016;35:42-9. doi:1016/j. drugpo.2015.11.008

22 Décary-Hétu D, Aldridge J. Sifting through the net: Monitoring of online offenders by researchers. European Review of Organised Crime 2015;2:122-41

23 Munksgaard R, Demant J, Branwen G. A replication and methodological critique of the study "Evaluating drug trafficking on the Tor Network". Int J Drug Policy 2016;35:92-6. doi:1016/j. drugpo.2016.02.027

24 Cunliffe J, Martin J, Décary-Hétu D, Aldridge J. An island apart? Risks and prices in the Australian cryptomarket drug trade. Int J Drug Policy 2017;50:64-73. doi:1016/j.drugpo.2017.09.005

25 Mireault C, Ouellette V, Décary-Hétu D, Crispino F, Broséus I. The potential for a forensic study of drug trafficking in Canada based on data collected on online cryptomarkets. Canadian Society of Forensic Science 2016;49:161-75. doi:1080/00085030.2016.1189229

26 Seago S, Hayek A, Pruszynski J, Newman MG. Change in prescription habits after federal rescheduling of hydrocodone combination products. Proc (Bayl Univ Med Cent) 2016;29:268-70. doi:1080/08998280.2016.11929431

27 Schultz S, Chamberlain C, Vulcan M, Rana H, Patel B, Alexander JC. Analgesic utilization before and after rescheduling of hydrocodone in a large academic level 1 trauma center. J Opioid Manag 2016;12:119-22. doi:5055/jom.2016.0323

28 Oehler EC, Day RL, Robinson DB, Brown LH. Has the rescheduling of hydrocodone changed ED prescribing practices? Am J Emerg Med 2016:34:2388-91. doi:1016/j.ajem.2016.09.002

29 Haynes A, Kleinschmidt K, Forrester MB, Young A. Trends in analgesic exposures reported to Texas Poison Centers following increased regulation of hydrocodone. Clin Toxicol (Phila) 2016;54:434-40. doi:3109/15563650.2016.1148720

30 Mort J, Kuschel L. Impact of the hydrocodone schedule change on opioid prescription patterns in South Dakota. Res Social Adm Pharm 2016;12:e6. doi:1016/j.sapharm.2016.05.017

31 Jones CM, Lurie PG, Throckmorton DC. Effect of US Drug Enforcement Administration's rescheduling of hydrocodone combination product on opioid analgesic prescribing. JAMA Intern Med 2016;176:399402. doi:1001/jamainternmed.2015.7799

32 Raji MA, Kuo YF, Adhikari D, Baillargeon J, Goodwin JS. Decline in opioid prescribing after federal rescheduling of hydrocodone products. Pharmacoepidemiol Drug Saf 2017;27:1-7.

33 LeQuang JA, Pergolizzi JV, Breve F, Taylor R. The Aftermath of Hydrocodone Rescheduling: Intentional and Unintended Consequences. Int I Anesth Res 2017:5:377-82

34 Beletsky L, Davis CS. Today's fentanyl crisis: Prohibition's Iron Law, revisited. Int J Drug Policy 2017;46:156-9. doi:1016/j. drugpo.2017.05.050

35 Décary-Hétu D, Aldridge J; DATACRYPTO: The dark net crawler and scraper [Computer software]; 2013.

36 Demant J, Munksgaard R, Décary-Hétu D, Aldridge J. Going local on a global platform. A critical analysis of the transformative potential of cryptomarkets for organized illicit drug crime. Int Crim Justice Rev [forthcoming].

37 Paquet-Clouston M, Décary-Hétu D, Morselli C. Assessing market competition and vendors' size and scope on AlphaBay. Int J Drug Policy 2018;54:87-98. doi:1016/j.drugpo.2018.01.003

38 Aldridge J, Décary-Hétu D. Hidden wholesale: The drug diffusing capacity of online drug cryptomarkets. Int J Drug Policy 2016;35:715. doi:1016/j.drugpo.2016.04.020

39 Décary-Hétu D, Paquet-Clouston M, Aldridge J. Going international? Risk taking by cryptomarket drug vendors. Int J Drug Policy 2016;35:69-76. doi:1016/j.drugpo.2016.06.003

40 Décary-Hétu D, Giommoni L. Do police crackdowns disrupt drug cryptomarkets? A longitudinal analysis of the effects of Operation Onymous. Crime Law Soc Change 2017;67:55-75. doi:1007/ s10611-016-9644-4

41 Christin N. Traveling the Silk Road: A measurement analysis of a large anonymous online marketplace; Proceedings of the 22nd international conference on World Wide Web; 2013; 213-24.

42 Aldridge, J, \& Décary-Hétu, D; Not an 'Ebay for Drugs': the Cryptomarket 'Silk Road' as a paradigm shifting criminal innovation; 2014; SSRN 2436643.

43 Broséus J, Rhumorbarbe D, Morelato M, Staehli L, Rossy Q. A geographical analysis of trafficking on a popular darknet market. Forensic Sci Int 2017;277:88-102. doi:1016/j. forsciint.2017.05.021

44 Kontopantelis E, Doran T, Springate DA, Buchan I, Reeves D. Regression based quasi-experimental approach when randomisation is not an option: interrupted time series analysis. BM/ 2015;350:h2750. doi:1136/bmj.h2750

45 Bernal JL, Cummins S, Gasparrini A. Interrupted time series regression for the evaluation of public health interventions: a tutorial. Int J Epidemiol 2017;46:348-55.

46 Nelson LS, Juurlink DN, Perrone J. Addressing the opioid epidemic IAMA 2015;314:1453-4. doi:1001/jama.2015.12397

47 Norbutas L. Offline constraints in online drug marketplaces: An exploratory analysis of a cryptomarket trade network. Int I Drug Policy 2018;56:92-100. doi:1016/j.drugpo.2018.03.016

48 Aldridge J, Stevens A, Barratt MJ. Will growth in cryptomarket drug buying increase the harms of illicit drugs? Addiction 2017.

49 Roehr B. Trump declares opioid public health emergency but no extra money. BMJ 2017;359:j4998. doi:1136/bmj.j4998

50 Roehr B. Health leaders blame addiction for US opioid crisis. BMJ; 2017;359; j4814.

51 Thornton M. Cato institute policy analysis no. 157: Alcohol prohibition was a failure. Cato Institute, 1991

52 MacCoun RJ, Reuter P. Drug war heresies: Learning from other vices, times, and places. Cambridge University Press, 2001. doi:1017/ CB09780511754272

Supplementary information: appendix tables 1 and 2 